\title{
What are the impacts of flow regime changes on fish productivity in temperate regions? A systematic map protocol
}

Trina Rytwinski ${ }^{1,2^{*}}$, Jessica J. Taylor ${ }^{1,2}$, Joseph R. Bennett ${ }^{1,3}$, Karen E. Smokorowski $^{4}$ and Steven J. Cooke ${ }^{1,2}$

\begin{abstract}
Background: Ecosystem changes from altered flows can have multiple impacts on fish, including changes to physical habitat, habitat access, food supplies, behaviour, community composition, energy expenditure, and population dynamics. There is growing evidence of the potential negative consequences of altered flow regimes on fluvial ecosystems and the fisheries they support. As such, the scientific and policy communities have acknowledged the need for maintaining or restoring natural flow variability in order to sustain ecological health of fluvial ecosystems. However, for resource managers, making decisions on the potential effects of flow alterations on fish productivity has been problematic because there are still uncertainties regarding flow-fish productivity relationships. Therefore, to ensure the maintenance of healthy and productive aquatic ecosystems and the sustainability of riverine fisheries, a better understanding of the impacts of flow alteration on fish productivity is needed. Due to the wide scope of this review, and the diversity of fish productivity outcomes used to evaluate flow alteration impacts, the set of studies will be quite heterogeneous. Therefore, prior to undertaking a comprehensive and quantitative synthesis, we propose to begin with a systematic map to provide an overview of the available evidence on the impacts of flow regime changes on fish productivity. We will also use this systematic map to identify subtopics that are sufficiently covered by existing studies to allow full systematic reviewing.
\end{abstract}

Methods: This systematic map will compile evidence on the impacts of flow regime changes on fish productivity. All studies that evaluate the effects of flow regime change on direct outcomes of fish productivity, will be included in the review. We will use a broad definition of fish productivity to include any measurement related to: biomass, abundance, density, yield, diversity, growth, survival, individual performance, migration, reproduction, recruitment, or surrogate thereof. Relevant causes of a change in/modification to flow regime can include: (1) anthropogenic causes: dams, reservoirs (impoundments), hydroelectric facilities, locks, levees, water withdrawal (abstraction), water diversion, land-use changes, and road culverts; or (2) natural causes: climate change (possible indirect anthropogenic cause as well), floods, droughts, seasonal changes. Any freshwater or estuarine fish species or species groups in temperate regions will be considered. The review will include a wide range of sources including primary and grey literature and use public databases, search engines and specialist websites. A searchable database containing extracted metadata from relevant included studies will be developed and provided as a supplementary file to the map report. The final narrative will describe the quantity and key characteristics of the available evidence, identify knowledge gaps for future research and identify subtopics that are sufficiently covered by existing studies to allow full systematic reviewing.

\footnotetext{
${ }^{*}$ Correspondence: trytwinski@hotmail.com

${ }^{1}$ Canadian Centre for Evidence-Based Conservation and Environmental

Management, Institute of Environmental Sciences, Carleton University,

Ottawa, ON, Canada

Full list of author information is available at the end of the article
} 
Keywords: Dam, Evidence-based policy, Fish biomass, Fish abundance, Fish density, Flow modification, Hydroelectric, Reservoirs, River regulation, Stream

\section{Background}

Flow regime strongly influences the ecological characteristics of river and stream ecosystems [1-4]. The natural flow paradigm stresses that the various components of the flow regime (i.e., the magnitude, frequency, duration, timing, and rate of change of flow events) play a direct or indirect role in maintaining the ecological integrity of the aquatic system [2]. Over evolutionary time, aquatic communities, including fish populations, have adapted to the inherent natural variability of rivers and streams [5]. As such, the importance of this natural flow variability in maintaining healthy fluvial ecosystems has recently become a primary focus for water resource managers, indicating the need for a better understanding of flowecosystem response relationships for effective management of these systems [6].

Many freshwater ecosystems are under increasing threat from anthropogenic activities and escalating human demands for water, which has led to alterations of natural flow regimes [7-9]. Flow alterations can result from many human modifications, including the construction of dams, hydroelectric facilities, water extraction for agriculture, drinking, industry, and recreation, and flood control measures $[10,11]$. Such changes of the natural flow regime may impact various chemical, physical, and biological attributes of rivers leading to declines in water quality, water supply, and the ecological integrity of river and stream ecosystems [12]. For example, in a review of the ecological effects of altered flow regimes, Poff and Zimmerman [13] found that 92\% of studies reported reductions in ecological metrics (e.g., changes in species or population abundance, demographic rates or community diversity for various taxonomic groups) in response to a variety of flow alterations.

Ecosystem changes from altered flows can have multiple impacts on fish, including changes to physical habitat, habitat access, food supplies, behaviour, community composition, energy expenditure, and population dynamics [14, 15]. For example, Haxton et al. [16] found that the relative abundance of lake sturgeon was lower in regulated rivers than in unregulated rivers in Ontario. Low flows resulting from dam construction in California were found to increase the growth of aquatic plants and thereby decrease Chinook salmon spawning habitat availability [17]. Fish abundance, demographic parameters, and diversity were found to consistently decline in response to both increases and decreases in flow magnitude (reviewed in Poff and Zimmerman [13] but also see Webb et al. [18]). Modifications of flows from natural regimes were associated with reduced abundance of fluvial specials but not habitat generalists (reviewed in Haxton and Findlay [19]). Fish productivity has also been shown to be affected by measures attempting to restore or control flow to rivers impacted by hydroelectric facilities. For example, in Newfoundland, the placement of hydraulic control structures on a $1.2 \mathrm{~km}$ long natural high flow, flood bypass channel of the Rose Blanche River provided constant regulated flow to an area that was previously only wetted during snow melt events. Monitoring of the impacts of this controlled flow over 3 years showed a steady increase in total fish biomass (an indicator of productivity) in the channel each year, achieving $128 \%$ of lost production by the third year (i.e., determined from comparisons to estimated biomass in pre-development surveys) [20].

\section{Topic identification and stakeholder input}

Given the abundant evidence for the potential negative impacts of altered flow regimes on fish, there is currently a strong consensus within the scientific and policy communities that maintaining or restoring, as close as possible, natural flow variability, is important for sustaining ecological health of rivers ecosystems and the fisheries they support [2, 21-23]. However, for water resource managers, decisions on the potential effects of flow alterations on fish productivity are difficult because there are still uncertainties in our understanding of flow-fish productivity relationships. As a result, a review of the impacts of flow alteration on fish productivity has been explicitly proposed by Canadian stakeholders [i.e., Fisheries and Oceans Canada (DFO)]. Due to the wide scope of such a review, and the diversity of fish productivity outcomes used to evaluate flow alteration impacts, the set of studies will be quite heterogeneous. Therefore, prior to undertaking a comprehensive and quantitative synthesis, we propose to begin with a systematic map to provide an overview of the available evidence on the impacts of flow regime changes on fish productivity.

During the formulation of the review question, an Advisory Team made up of stakeholders and experts was established and consulted. This team included US and Canadian academics, and staff from Fisheries and Oceans Canada (DFO), specifically the Fisheries Protection Program (FPP), and DFO Science Branch. The Advisory Team guided the focus of this review to ensure the primary question was both answerable and relevant, and 
suggested search terms to capture the relevant literature. The Advisory Team was also consulted in the development of the inclusion criteria for article screening and the list of specialist websites for searches.

\section{Objective of the map}

The proposed systematic map is intended to provide an overview of the existing literature base on the impacts of flow regime change on fish productivity in freshwater and estuarine fluvial environments. Through this systematic mapping exercise, we will describe the quantity and key characteristics of the available evidence, identify evidence clusters, and knowledge gaps. The systematic map will also identify subtopics that are sufficiently covered by existing studies to allow full systematic reviewing.

\section{Primary question}

What are the impacts of flow regime changes on fish productivity in temperate regions?

\section{Components of the primary question}

The primary study question can be broken down into the study components:

\section{Population}

Intervention/exposure

Comparator

Outcomes freshwater and estuarine fish in temperate regions

changes to (or manipulations of) flow regime

no intervention or alternative levels of intervention

change in a component of fish productivity (broadly defined in terms of: biomass, abundance, density, yield, diversity, growth, survival, individual performance, migration, reproduction, recruitment, or a surrogate thereof)

\section{Methods}

Searches

Search terms

A list of relevant search terms was generated by the Advisory Team, and broken into three components: the population (subject and environment type/cause of intervention), intervention/exposure and outcome, and will be combined using Boolean operators "AND" and/or "OR" (Table 1).

The asterisk (*) is a wildcard and represents any characters, including no character (e.g., Reproduc* includes Reproduce, Reproducing, Reproduces, Reproduced) while the dollar sign (\$) includes zero or one character (e.g., Stream\$ includes Stream or Streams). Phrases in quotation marks were used to search exact phrases (e.g., "fresh water" includes the exact phrase fresh water as well as the hyphenated version fresh-water). When a complex search string or wildcards are not accepted by the database or search engine, the help menu will be consulted and the search terms will be customised. Final search terms will be recorded for each search in an appendix.

English search terms will be used to conduct all searches in all databases and search engines. All references that are returned will be included in the database. Articles with only abstracts in English but full texts in other languages that are of potential relevance will be recorded separately. However, only English language literature will be included during the screening stage. No date or document type restrictions will be applied. Where books are identified, digital copies will be sought (either through internet searches for availability or requests to authors) in order to ensure that all obtainable records are made available as an output from this review. In cases where digital copies are not available, books will still be considered for inclusion.

The search strategy has been developed to include a variety of article types, including primary literature in peer-reviewed journals and grey literature (e.g., theses, government papers, organisation reports, consultant

Table 1 Proposed search string for the execution of the search strategy

\begin{tabular}{|c|c|}
\hline Component & Search string \\
\hline \multirow[t]{2}{*}{ Population terms } & $\begin{array}{l}\text { [Fish* AND ("Fresh water" OR Freshwater OR Stream\$ OR Water\$ OR River\$ OR Fluvial OR Lake\$ OR Pond\$ OR Wetland\$ } \\
\text { OR Estuar* OR Reservoir\$ OR Canal\$ OR Impoundment\$ OR "Hydro electric*"OR Hydroelectric* OR "Hydro dam*" } \\
\text { OR Hydrodam** OR "Hydro power" OR Hydropower OR "Hydro" OR Dam\$ OR Withdraw* OR Diversion\$ OR "Climate } \\
\text { change")] }\end{array}$ \\
\hline & AND \\
\hline \multirow[t]{2}{*}{ Intervention/exposure terms } & $\left(\right.$ Flow $^{*}$ OR Discharg*) \\
\hline & AND \\
\hline Outcome terms & $\begin{array}{l}\text { (Productivity OR Growth OR Performance OR Surviv* OR Success OR Migrat* OR Passag* OR Reproduc* OR Biomass } \\
\text { OR Stress* OR Disease\$ OR Mortalit* OR Abundance\$ OR Densit* OR Recruit* OR Yield\$ OR "Ecological response" OR } \\
\text { "Ecosystem response" OR "Biotic response") }\end{array}$ \\
\hline
\end{tabular}


reports, etc.). The search strategy will strive to minimize publication biases by focussing efforts equally on each article type and putting equal weight on the information provided in each article type.

\section{Publication databases}

The following online databases will be searched.

1. Waves (Fisheries and Oceans Canada)-Canadian government books, reports, government documents, theses, conference proceedings, and journal titles.

2. ProQuest Dissertations \& Theses Global-collection of dissertations and theses from around the world, spanning from 1743 to the present.

3. Science.gov-US Federal Science.

4. ISI Web of Science Core Collection-multidisciplinary research topics including journals, books, proceedings, published data sets and patents.

5. Scopus-abstract and citation database of peerreviewed literature including journals, books, and conference proceedings.

6. AGRICOLA (Agricultural Research Database)-US Department of Agriculture's National Agricultural Library.

\section{Search engines}

Internet searches will be performed using the search engine Google Scholar, and the first 500 hits (sorted by relevance) will be screened for the appropriate fit for the review question. Similar to database searches, customized search strings used in search engines (and specialist websites below) will be recorded in an appendix.

\section{Specialist websites}

Specialist organization websites listed below will be searched using connectors created in Import.io and abbreviated search terms [i.e., search strings (1) fish AND flow AND regime; (2) fish AND flow AND alter; (3) fish AND hydro AND discharge; and (4) modified AND flow AND regime]. Page data from the first 20 search results for each search string will be extracted, screened for relevance, and searched for links or references to relevant publications, data and grey literature. The list of websites was narrowed to the following 29 organizations after consulting with our Advisory Team for relevance.

1. Alberta Hydro

2. British Columbia Hydro

3. Centre for Ecology and Hydrology

4. Centre for Environment, Fisheries and Aquaculture Science
5. Commonwealth Scientific and Industrial Research Organisation

6. Electric Power Research Institute

7. Fisheries and Oceans Canada

8. Fisheries Research Service

9. Food and Agriculture Organization of the United Nations

10. Hydro-Québec

11. Land and Water Australia

12. Manitoba Hydro

13. Ministry of the Environment New Zealand

14. Ministry of Natural Resources and Environment of the Russian Federation

15. National Institute of Water and Atmospheric Research

16. National Institute of Water and Atmospheric Research New Zealand

17. Natural Resources Canada

18. Natural Resources Wales

19. Newfoundland and Labrador Hydro

20. Northern Ireland Environment Agency

21. Ontario Ministry of Natural Resources

22. Ontario Power Generation

23. Pacific Fisheries Environmental Laboratory

24. Parks Canada

25. The Nature Conservancy

26. Trout Unlimited

27. TNC E-flows Initiative

28. United Nations Environment Programme

29. US Fish and Wildlife Service

\section{Other literature searches}

Reference sections of accepted articles will be hand searched to evaluate articles that have not been found using the search strategy. Authors of any unpublished references will be contacted to request access to the full article. Stakeholders will be consulted for insight and advice for new sources of information. The Review Team will contact authors of unobtainable articles in an attempt to gain access to the full article. We will also use social media and email to alert the community of this systematic map and to reach out to recognized experts and practitioners for further recommendations and for provision of relevant unpublished material. Any article provided will also be used to test the comprehensiveness of our search strategy and, where appropriate, adjustments will be made to the search strategy to ensure it is comprehensive and inclusive. Sources of all information retrieved from these other literature searches will be recorded in the database. Any changes made to the search strategy will be justified and documented in the final review document. 


\section{Search record database}

All articles generated by database and search engine search strategies will be exported into separate Zotero databases. After all searches have been completed and references found using each different strategy have been compiled, the individual databases will be exported in to EPPI-reviewer as one database. Duplicates will be identified and merged. All references regardless of their perceived relevance to this systematic review will be included in the database. This database will act as the archive and will remain unchanged throughout the review process, since it is the direct product of the search strategy and will be useful in the future when updating the systematic review archive (general updating timeframe is currently every 5 years).

\section{Article screening and study inclusion criteria Screening process and inclusion criteria}

Articles found by searches in databases and search engines will be screened in two distinct stages: (1) title and abstract, and (2) full text. Before the screening of title and abstracts begins, two reviewers using a random subset of $10 \%$ of all articles or 100 abstracts (whichever is bigger) will undertake consistency checks to ensure consistent and repeatable decisions are being made in regards to which articles get screened out and which go on in the process to be further reviewed. The two reviewers will use a Kappa test to determine consistencies in screening decisions. A Kappa score of $\geq 0.6$ indicates substantial agreement between reviewers and will be required to be achieved before any further screening is conducted for the review. The results from the consistency check will be discussed and discrepancies will be reviewed by both reviewers to understand why the choice was made to include/exclude the article. This same process will be repeated prior to screening articles at full text i.e., two reviewers using a random subset of $10 \%$ of all articles that were included at title and abstract, will undertake consistency checks and a Kappa score of $\geq 0.6$ will be required before any further screening is conducted. Articles or datasets found by other means than database or search engine searches (i.e., specialist website or other literature searches) will be entered at the second stage of this screening process (i.e., full text) but will not be included in consistency checks.

All article screening decisions will be included in the database, so it will be clear at what level any article was excluded. If the decision to include or exclude a specific article is unclear, that article will be retained and will go on to the next level of screening. If there is further doubt, the Review Team will discuss those articles as a group to come up with a decision. Any articles that do not have abstracts will automatically be screened at the full text level. Justification of the reason for inclusion or exclusion of an article will be explained and recorded using EPPI reviewer, and an additional file of all articles excluded at the full text, together with reasons for exclusion, will be included with the review.

Articles will be excluded based on the following predefined inclusion criteria developed in consultation with the Advisory Team:

\section{Relevant subjects}

Any fish species in North $\left(23.5^{\circ} \mathrm{N}-66.5^{\circ} \mathrm{N}\right)$ or South $\left(23.5^{\circ} \mathrm{S}-66.5^{\circ} \mathrm{S}\right)$ temperate regions. Fish can be resident (i.e., non-migratory) or migratory, including diadromous species (e.g., fish that migrate between fresh and salt water), and at any life stage. This can also include species that have been stocked or invasive, and are now established in a waterbody. Only studies located in freshwater or estuarine fluvial (i.e., water moving via gravity) ecosystems, including lakes, rivers, and streams will be included.

\section{Relevant interventions/exposures}

Articles that describe a change in, or modification to, a component of flow regime. Components of flow regime can include: magnitude, frequency, duration, timing (seasonality), rate of change, or surrogate thereof (e.g., water velocity or depth). Relevant causes of a change in/modification to flow regime can include: (1) anthropogenic causes: dams, reservoirs (impoundments), hydroelectric facilities, locks, levees, water withdrawal (abstraction), water diversion, land-use changes, and road culverts; or (2) natural causes: climate change (possible indirect anthropogenic cause as well), floods, droughts, seasonal changes.

\section{Relevant comparators}

Relevant comparators will include: (1) similar sections of the same waterbody with no intervention (i.e., upstream condition); (2) separate but similar waterbodies with no intervention; (3) before intervention data within same waterbody (i.e., pre-construction/modification); (4) an alternative level of intervention on the same or different study waterbody, or (5) controlled flume study. Studies that evaluate temporal or spatial trends of relevant outcomes related a change in, or modification to flow regime, will also be included. Studies which measure a single point in time, with no comparison to another site will be excluded.

\section{Relevant outcomes}

The reported measured effect should indicate some change in a component of fish productivity. We will use a broad definition of fish productivity to include any 
measurement related to: biomass, abundance, yield, diversity, density, growth, survival, individual performance, migration, reproduction, recruitment, sustainability, population viability, persistence, stress, or surrogate thereof. Only studies that evaluate a direct response (outcome) of some aspect of fish productivity listed above (e.g., migration, abundance, reproduction) will be included. Studies that only evaluate an indirect response to altered flow i.e., authors make an indirect link between the measured outcome of altered flow (e.g., growth of aquatic plants) and its "potential" impact on fish (e.g., spawning habitat availability), will be excluded. Indirect outcomes can include, for example: (1) nutrients (e.g., amount/concentration), food supply (e.g., amount of plankton), infection/disease rate (e.g., parasites).

\section{Relevant types of study design}

Study designs with appropriate comparators including before/after (BA), control/impact (CI), as well as studies combining these types of comparisons, before/after/ control/impact (BACI) and Randomized Controlled Trials (RCT; e.g., lab or small in field manipulations) will be included. Theoretical studies, review papers and policy discussions will be excluded.

Critical appraisal of study validity No critical appraisal will be made of studies subsequent to their inclusion in the review because the scope of the topic and the highly heterogeneous nature of the studies would make this incredibly complex and difficult. Meta-data on aspects of study setting and design will be extracted from included studies to provide a very basic overview of the robustness and relevance of the evidence. However, the primary purpose of extracting this meta-data would be to aid future more in depth critical appraisal and synthesis of studies on sub-topics of interest identified from this systematic map exercise.

\section{Data coding strategy}

Information on coding variables will be extracted from the included studies following full-text screening by the Review Team. The following main categories of descriptive data will be extracted: (1) bibliographic information; (2) study location (e.g., geographic location, waterbody type etc.); (3) study design; (4) intervention/exposure type; (5) cause of intervention; (6) comparator type; (7) outcome type; and (8) species (or species groups) studied. To ensure that data are being extracted in a consistent and repeatable manner, two reviewers will extract information from ten of the same articles at the beginning of the process. Afterwards, the information will be compared. Any inconsistencies will be discussed amongst the Review Team members, and if any disagreement occurs, they will be discussed with the entire Review Team to ensure all reviewers are extracting and interpreting data in the same manner.

\section{Study mapping and presentation}

All included studies and their meta-data will be recorded in a MS-Excel database that will be made available with the published systematic map article, as additional supporting files. The final narrative report will describe the review process and the volume and key characteristics of the evidence base, detailing methodology, results and trends, identifying possible knowledge gaps (i.e., subtopics requiring further primary research) and evidence clusters. The systematic map will also identify subtopics that are sufficiently covered by existing studies to allow full systematic reviewing.

\section{Authors' contributions}

The manuscript was drafted by TR. JJT, KES, JRB, and SJC provided comments and revisions. All authors read and approved the final manuscript.

\section{Author details \\ ${ }^{1}$ Canadian Centre for Evidence-Based Conservation and Environmental Man- agement, Institute of Environmental Sciences, Carleton University, Ottawa, ON, Canada. ${ }^{2}$ Fish Ecology and Conservation Physiology Laboratory, Department of Biology, Carleton University, Ottawa, ON, Canada. ${ }^{3}$ Department of Biol- ogy and Institute of Environmental Science, Carleton University, Ottawa, ON, Canada. ${ }^{4}$ Great Lakes Laboratory for Fisheries and Aquatic Sciences, Fisheries and Oceans Canada, Sault Ste. Marie, ON, Canada.}

\section{Acknowledgements}

The authors would like to thank several reviewers and collaborators who provided valuable insights to strengthen this review protocol including: Julian Olden (University of Washington, USA), Daniel Boisclair (Université de Montréal, CA), and Fisheries and Oceans Canada staff including Richard Janusz, Keith Clarke, Mike Bradford, Andrea Doherty, Haitham Ghamry, Brendan Spearin. We also thank the reviewers for their constructive comments.

\section{Competing interests}

The authors declare that they have no competing interests.

\section{Funding}

The study was supported by Fisheries and Oceans Canada, and the Natural Sciences and Engineering Research Council of Canada.

\section{Publisher's Note}

Springer Nature remains neutral with regard to jurisdictional claims in published maps and institutional affiliations.

Received: 16 November 2016 Accepted: 22 May 2017

Published online: 30 May 2017

\section{References}

1. Power ME, Sun A, Parker G, Dietrich WE, Wootton JT. Hydraulic food-chain models. Bioscience. 1995;45:159-67.

2. Poff NL, Allan JD, Bain MB, Karr JR, Prestegaard KL, Richter BD, Sparks RE, Stromberg JC. The natural flow regime: a paradigm for river conservation and restoration. Bioscience. 1997;47:769-84.

3. Bunn SE, Arthington AH. Basic principles and ecological consequences of altered flow regimes for aquatic biodiversity. Environ Manag. 2002;30:492-507. 
4. Olden JD, Poff NL. Redundancy and the choice of hydrologic indices for characterizing streamflow regimes. River Res Appl. 2003;19:101-21.

5. Lytle DA, Poff NL. Adaptation to natural flow regimes. Trends Ecol Evol. 2004:19:94-100.

6. Gillespie BR, Desmet S, Kay P, Tillotson MR, Brown LE. A critical analysis of regulated river ecosystem responses t o managed environmental flows from reservoirs. Freshw Biol. 2015;60:410-25.

7. Tharme RE. A global perspective on environmental flow assessment: emerging trends in the development and application of environmental flow methodologies for rivers. River Res Appl. 2003;19:397-441.

8. Ritchter BD, Davis MM, Apse C, Konrad C. A presumptive standard for environmental flow protection. River Res Appl. 2012;28:1312-21.

9. Bradford MJ, Randall RG, Smokorowski KS, Keatley BE, Clarke KD. A framework for assessing fisheries productivity for the Fisheries Protection Program. DFO Can Sci Advis Sec Res Doc. 2013. http://www.dfo-mpo. gc.ca/csas-sccs/publications/resdocs-docrech/2013/2013_067-eng.pdf. Accessed 27 Sept 2016.

10. Gleick PH. Global freshwater resources: soft-path solutions for the $21 \mathrm{st}$ century. Science. 2003;302:1524-8.

11. Enders EC, Scruton DA, Clarke KD. The 'Natural Flow Paradigm' and Atlantic salmon - moving from concept to practice. River Res Appl. 2009;25:2-15.

12. Richter BD, Baumgartner JV, Wigington R, Braun DP. How much water does a river need? Freshw Biol. 1997;37:231-49.

13. Poff NL, Zimmerman JKH. Ecological responses to altered flow regimes: a literature review to inform the science and management of environmental flows. Freshw Biol. 2010;55:194-205.

14. Clark KD, Pratt TC, Randall RG, Scruton DA, Smokorowski KE. Validation of the flow management pathway: effects of altered flow on fish habitat and fishes downstream from a hydropower dam. DFO Can Tech Rep Fish Aquat Sci. 2008. http://www.dfo-mpo.gc.ca/Library/332113.pdf. Accessed 6 Oct 2016.

15. Murchie KJ, Hair KPE, Pullen CE, Redpath TD, Stephens HR, Cooke SJ. Fish response to modified flow regimes in regulated rivers: research methods, effects and opportunities. River Res Appl. 2008;24:197-217.

16. Haxton T, Friday M, Cano T, Hendry C. Assessing the magnitude of effect of hydroelectric production on Lake Sturgeon abundance in Ontario. N Am J Fish Manag. 2015;35:930-41.

17. Merz JE, Smith JR, Workman ML, Setka JD, Mulchaey B. Aquatic macrophyte encroachment in Chinook Salmon spawning beds: lessons learned from gravel enhancement monitoring in the Lower Mokelumne River, California. N Am J Fish Manag. 2008;28:1568-77.

18. Webb JA, Miller KA, King EL, de Little SC, Stewardson MJ, Zimmerman $\mathrm{JKH}$, Poff NL. Squeezing the most out of existing literature: a systematic re-analysis of published evidence on ecological responses to altered flows. Freshw Biol. 2013;58:2439-51.

19. Haxton T, Findlay CS. Meta-analysis of the impacts of water management on aquatic communities. Can J Fish Aquat Sci. 2010;65(3):437-47.

20. Scruton DA, Clarke KD, Roberge MM, Kelly JF, Dawe MB. A case study of habitat compensation to ameliorate impacts of hydroelectric development: effectiveness of re-watering and habitat enhancement of an intermittent flood overflow channel. J Fish Biol. 2005;67:244-60.

21. Postel S, Richter B. Rivers for life: managing water for people and nature. Washington: Island Press; 2003.

22. King J, Brown C. Environmental flows: striking the balance between development and resource protection. Ecol Soc. 2006;11:26.

23. Pittock J, Lankford BA. Environmental water requirements: demand management in an era of water scarcity. J Integr Environ Sci. 2010;7:75-93.

\section{Submit your next manuscript to BioMed Central and we will help you at every step:}

- We accept pre-submission inquiries

- Our selector tool helps you to find the most relevant journal

- We provide round the clock customer support

- Convenient online submission

- Thorough peer review

- Inclusion in PubMed and all major indexing services

- Maximum visibility for your research

Submit your manuscript at www.biomedcentral.com/submit
O Biomed Central 